\title{
Innovation in the educational technology course for pre- service student teachers in East China Normal University
}

\author{
Hanbing Yan \\ East China Normal University \\ Yumin Xiao \\ East China Normal University \\ Qiyun Wang \\ Nanyang Technological University
}

\begin{abstract}
Modern Educational Technology is a common course in many normal universities in China. The Modern Educational Technology Center (METC) of East China Normal University (ECNU) decided to improve the course for pre-service teachers at the end of 2010. The enhanced course has some additional features, such as emphasising knowledge and skills transfer, adopting a 4C/ID model to improve the course content, focusing on common technologies as well as cutting-edge technologies, and creating a supportive learning environment by using an online platform. The METC piloted this course in the first semester of 2011. Feedback was collected from a tentative survey, the student teachers' evaluation of teaching, and their online reflections. The result indicated that the participants became more confident in designing micro e-learning courses and more interested in the field of educational technology after they completed this course. This paper describes the conceptual framework of the course, its new features, and the evaluation results.
\end{abstract}

\section{Introduction}

In China, the training of educational technology competency for in-service teachers is usually designed and implemented under the supervision of Educational Technology Competency Standards for Teachers (Trial) (MOE, 2004). However, there are no existing guidelines for the training of pre-service teachers' ICT competencies. In many normal universities, Modern Educational Technology is a course commonly offered by the universities, but the content is usually decided by individual teachers. Furthermore, there are no well-organised principles to guide the design and evaluation of the course. Therefore, the quality of the course is often questioned by experts. Problems commonly mentioned in the literature include: low technology integration; simple models and single methods for teaching and learning; and lack of opportunities to practise; it has not represented the specific disciplinary features of educational technology; and the latest technology is seldom covered in the course (Chen, 2006; Cheng, 2007; Zhao, 2010).

East China Normal University (ECNU) is one of the key normal universities directly under the administration of the Chinese Ministry of Education (MOE). In ECNU, student teachers are required to take the Modern Educational Technology course in the 
third year. The course had been offered for 11 years by the METC till 2010. At the end of 2010, the METC decided to further improve the course after conducting a comprehensive analysis on the student teachers' technology knowledge and skills, aptitude for learning, and the requirements of curriculum reform.

\section{Conceptual framework}

\section{Varied features of student teachers}

Compared with in-service teachers, student teachers are varied in two aspects. On the one hand, they have no experience of teaching, little experience of designing learning activities or solving teaching problems. As a result, they may be able to propose innovative ideas for using technology, but will be restricted by limited understanding of strategies for instructional planning (Zhang \& Chen, 2008). On the other hand, the current student teachers are described as the new 'Net Generation' (Tapscott, 1998), who are familiar with and dependent on new technologies (Kennedy, Krause, Judd, Churchward \& Gray, 2008). So the METC attempted to provide more opportunities for the student teachers to explore and apply technologies in the course.

\section{Whole-task models and the 4C/ID model}

There has been growing interest in whole-task models of learning and instructional design in recent years. Whole-task models support the development of educational programs for students who need to learn and transfer professional competencies or complex cognitive skills to an increasingly varied set of real-world contexts and settings (Van Merriënboer \& Kester, 2007). The four-component instructional design model (4C/ID) is a classic example of whole-task models, which claims that the whole task environment for complex learning can always be divided into four components as shown in Figure 1 (Van Merriënboer, Clark \& de Croock, 2002):

- Learning task - Meaningful whole-task experiences that are based on real-life tasks;

- Supportive information - Information that is supportive to learning and performance, problem solving, and learning task reasoning;

- Procedural information - Information that is prerequisite to learning and performance of routine aspects of learning tasks;

- Part-task practice - Additional exercises for routine aspects of learning tasks with high level of automaticity after the instruction.

The 4C/ID model was adopted to guide the course improvement, as it is useful for student teachers to learn complex cognitive skills.

\section{Course features}

Based on the above conceptual framework, the expert group in the METC started to redesign the Modern Educational Technology course according to the features of student teachers and the 4C/ID model.

\section{Feature 1: Focusing on inquiry-based learning}

In real teaching practices, teachers often have opportunities to use different teaching and learning models, such as teacher-delivered instruction, problem-based learning, 
project-based learning, simulation-based learning, inquiry-based learning, collaborative learning, or case studies. Since class hours and student teachers' teaching experiences are limited, it is impossible for pre-service teachers to explore many technological tools and learn many instructional models within the class hours. Therefore, the expert group intended to find out critical factors that could empower student teachers to improve their knowledge and skills. After analysing their backgrounds, the METC found out that the student teachers were quite familiar with and had good understanding of teacher-delivery models. As to other models, they might know a little of the main concepts, but lacked sufficient experience with applying them. In the end, the METC decided that learning contents and instructional design should be focused on an inquiry-based learning approach, which would take advantage of student teachers' innovative ideas, and not be unduly restricted by the limitations in their actual teaching experience. For inquiry-based learning, WebQuest was chosen as a template to develop the course, as it has detailed guidelines to follow (Dodge, 2002).

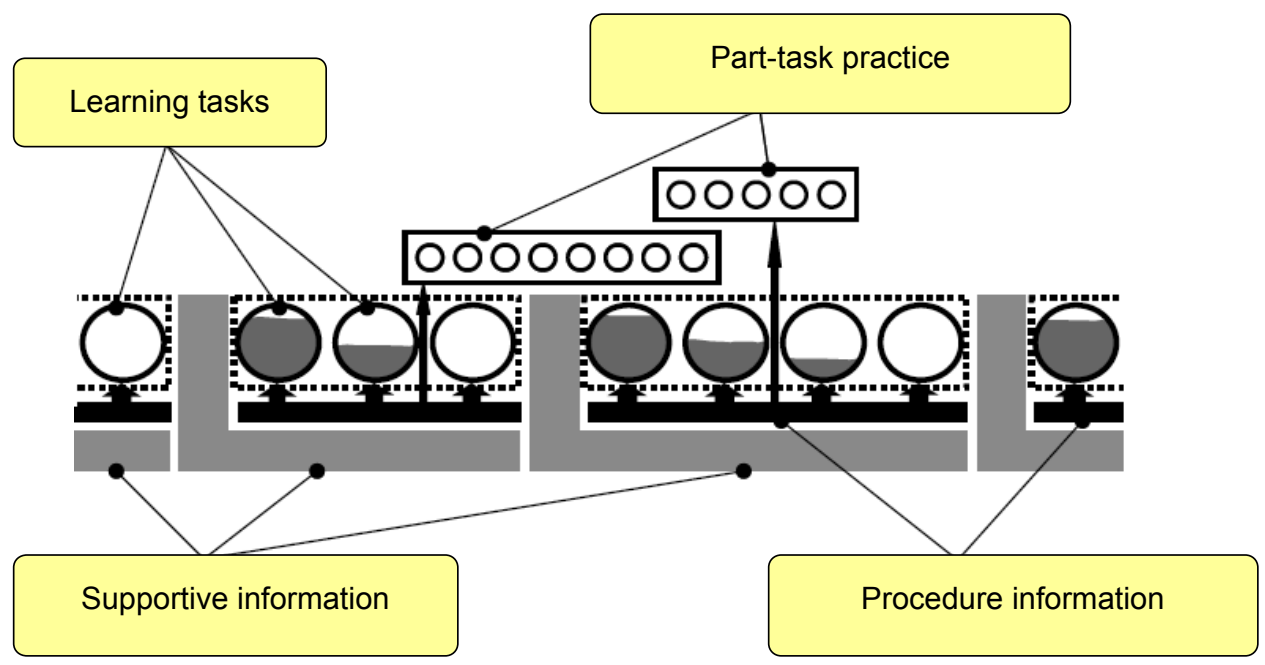

Figure 1: A schematic overview of the $4 \mathrm{C} / \mathrm{ID}$ model (Van Merriënboer \& Kirschner, 2008)

\section{Feature 2: Designing the course based on the 4C/ID model}

The expert group followed the 4C/ID model to integrate instructional concepts, teaching methods, and technologies into a whole task. The four critical components of the $4 \mathrm{C} / \mathrm{ID}$ model were associated with the following:

- Learning tasks: In the first lesson, student teachers would be given a task:

As an intern teacher, you are asked by your mentor to develop an inquirybased learning program for a class. You have to design an overall plan by following the WebQuest template for the program with all the technology resources you can find.

This task would be accomplished in the six sessions throughout the course. The task guidance, scaffolds, and specific sub-tasks for each learning activity would be provided in each session. 
- Supportive information: In each session, the rationale for course design, teaching and learning strategies, and instructions for technology integration were distributed and used as supportive information.

- Part-task practice: Intensive practices were provided to help student teachers learn instructional methods and technologies.

- Procedural information: In the course, a large number of guidelines, frameworks and rubrics were provided to support student teachers when they were engaged in self-directed learning.

\section{Feature 3: Emphasising knowledge and skill transfer}

As the nature of the course is to instruct student teachers how to use technologies to support teaching and learning, the course focused on: i) demonstrate to the students teachers about technology use; and ii) reflect the features of student-centered learning and enable them to construct meaning based on what they have learnt. In addition, the knowledge and skills that a teacher should embody in teaching, such as learning engagement, multi-assessment, learning scaffolding, collaborative learning and taskdriven, would also be experienced by student teachers in the course. This would allow them to naturally transfer the knowledge and skills from the course into their future teaching.

\section{Feature 4: Involving widely used technology as well as cutting-edge technology}

To assist student teachers in effective technology integration, the course classified technologies into three levels: technology to be acquired, technology to be familiar with, and technology to be aware of. Also, the course particularly emphasised the integration of technologies into teaching and learning processes. Various instructional methods were also provided for student teachers to learn technology from the three levels. Table 1 shows the technology tools student teachers learnt in the course and the main concerns in the instructional design of the course.

Table 1: Technology student teachers learnt in this course

\begin{tabular}{|c|c|c|}
\hline Levels & Examples & Main concerns in instructional design \\
\hline $\begin{array}{l}\text { - Technology to } \\
\text { be acquired }\end{array}$ & $\begin{array}{ll}\text { - } & \text { PowerPoint } \\
\text { - } & \text { Word } \\
\text { - } & \text { Publisher } \\
\text { - } & \text { Snagit } \\
\text { - } & \text { Movie Maker }\end{array}$ & $\begin{array}{ll}\text { - } & \text { Creating products } \\
\text { - } & \text { Supporting comprehensive } \\
& \text { instructional design }\end{array}$ \\
\hline $\begin{array}{l}\text { - Technology to } \\
\text { be familiar } \\
\text { with }\end{array}$ & $\begin{array}{ll}\text { - } & \text { Moodle } \\
\text { - } & \text { Blog } \\
\text { - } & \text { Wiki } \\
\text { - } & \text { Baihui } \\
\end{array}$ & $\begin{array}{ll}- & \text { Experiencing } \\
\text { - } & \text { Collaborative inquiring } \\
\text { - } & \text { Peer explanation }\end{array}$ \\
\hline $\begin{array}{l}\text { - Technology to } \\
\text { be aware of }\end{array}$ & $\begin{array}{ll}\text { - } & \text { The concept of Web } 2.0 \\
\text { - } & \text { Cloud computing } \\
\text { - } & 1: 1 \text { learning } \\
\text { - } & \text { Mobile learning }\end{array}$ & $\begin{array}{ll}\text { - } & \text { Introducing } \\
\text { - } & \text { Referring } \\
\text { - } & \text { Experiencing }\end{array}$ \\
\hline
\end{tabular}




\section{Feature 5: Creating a supportive learning environment by using an online platform}

In the field of educational technology, the importance of distance education can hardly be ignored. Therefore, distance education also should be integrated into the course and supported by a specially designed online platform (http://sfs.dec.ecnu.edu.cn/). As a supplementary tool for face to face teaching, this platform does not only provide learning materials, but also other necessary tools such as Moodle, blogs and wikis. Figure 2 shows a screen shot of the learning platform. Through these components, student teachers could complete and deliver their homework, reflect on what they learnt, and create or share their works. Meanwhile, they were provided with additional chances to experience Web 2.0 tools.

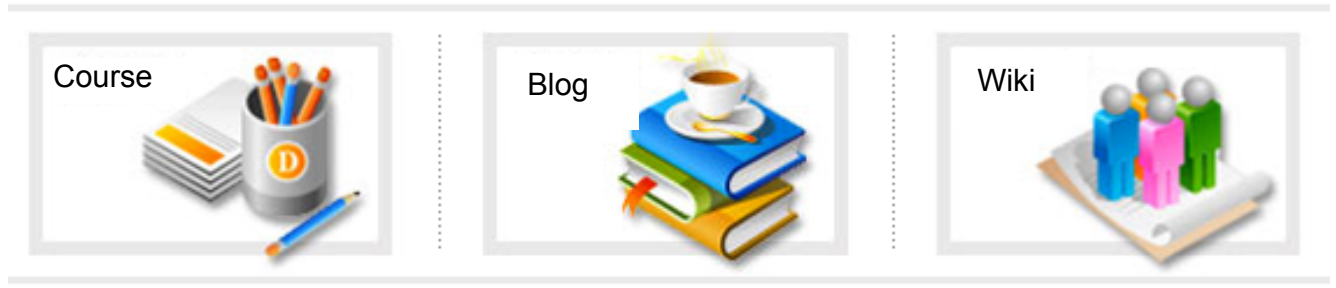

Figure 2: Screenshot of the instructional components of the learning platform

\section{Feature 6: Using multiple assessment tools to track learning processes}

When the course was implemented, the instructor could use various assessment methods and tools to monitor the student teachers' learning outcomes. The tools included pre-learning questionnaire, learning portfolios, individual product rubrics, peer evaluation based on rubrics, post-learning questionnaire, reflection on learning strategies, reflection on technology experienced in the course, and blogging about what was learnt. The use of the tools would engage student teachers in the learning process, and also would enable instructors to monitor their learning progress step by step.

\section{Tentative feedback results}

At the beginning of 2011, the newly enhanced Modern Educational Technology course was taken by 620 student teachers who were majoring in different subjects such as history, psychology, pre-school education, geography, and chemistry. Six weeks later, when the course was completed, some feedback was collected from the course participants through different channels. This feedback was generally positive.

First, students' evaluation of teaching was positive. There were all together 14 instructors who were teaching the course in that semester. The average score of students' evaluation on all instructors was 4.611, and the highest score for an instructor was 4.983 ( 5 is considered as perfect, and above 4.5 is excellent). It was a new record for the teaching group since this course was offered. To a certain extent, the high scores of students' evaluation of teaching were more likely to imply the high quality of the course, as all instructors followed the same teaching syllabus and schedules. 
Second, positive feedback came from a tentative survey of the participants. After completing the course, student teachers were asked to complete an online questionnaire. The questionnaire was co-designed by the instructors in the teaching group after seeking advice from experts at the METC. The questionnaire consisted of 21 questions: 6 were to obtain information on student teachers' participation in the course, including time and frequency of learning; 9 were related to their feeling about their instructor; and the rest were about the design of the course, and two of which (in a 5-point Likert scale format) were to collect their perceptions of the course design. A total of 570 valid responses were collected. The results of the two questions are illustrated in the following figures. Figure 3 shows that a majority (more than 90\%) of the participants became more confident in designing micro e-learning courses after completing the course. Figure 4 further displays that most of them became more interested in educational technology after taking the course.

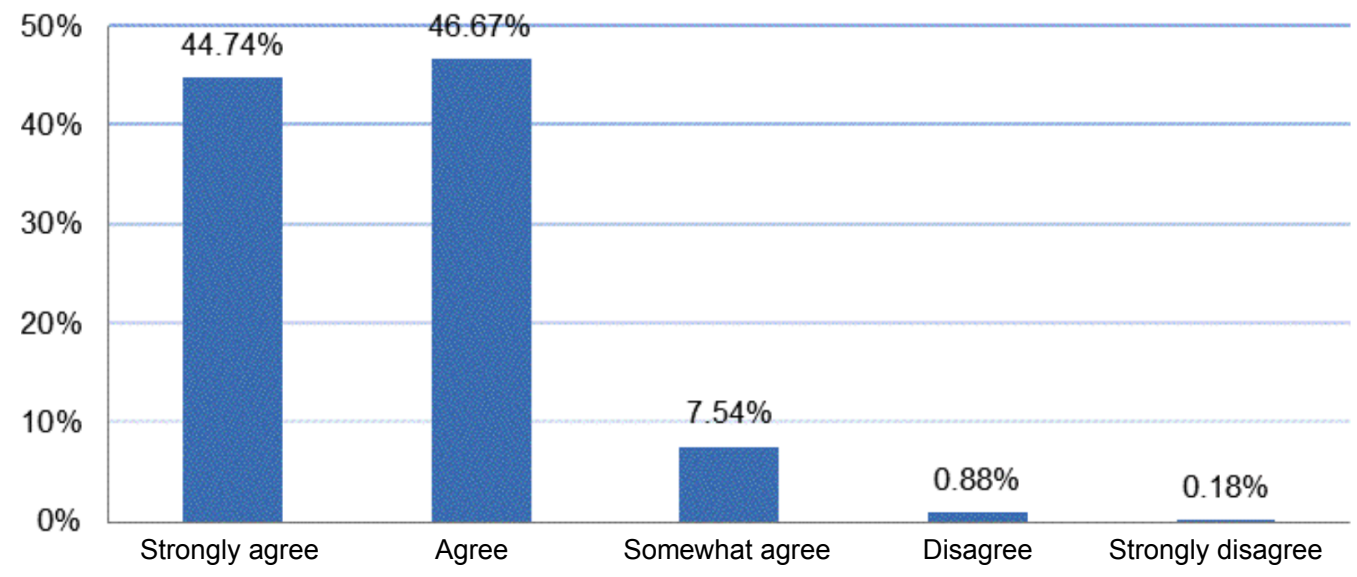

Figure 3: Feedback about student teachers' confidence

Question 1: I have become confident in designing a micro e-learning course after I studied this course

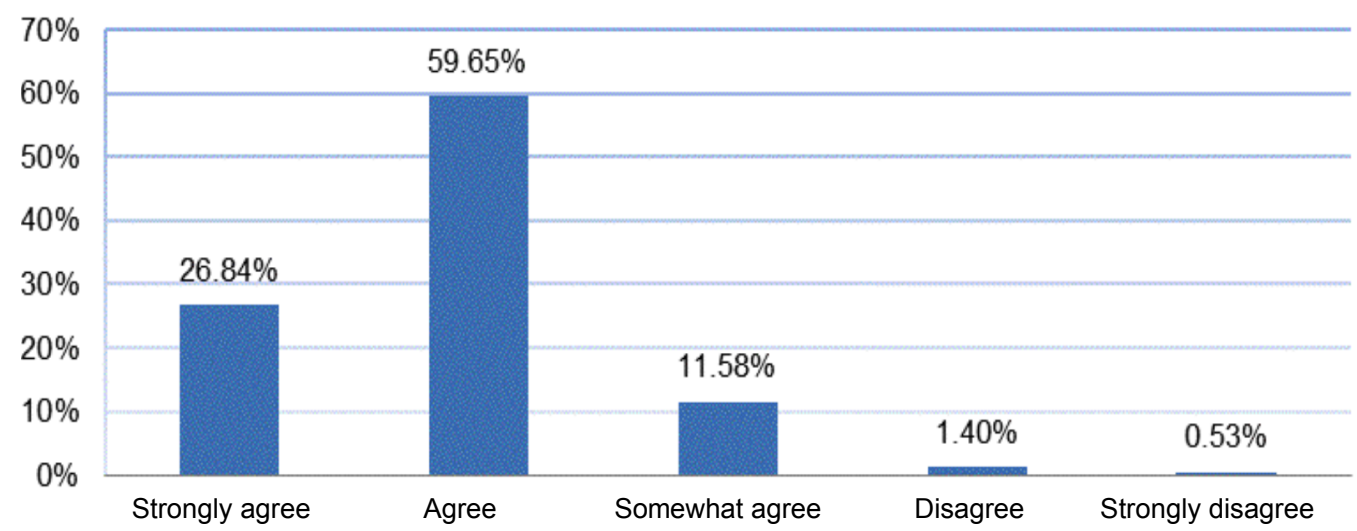

Figure 4: Feedback about student teachers' interest

Question 2: I began to be interested in the field of educational technology after I studied this course 
Third, students' blogs (http://sfs.dec.ecnu.edu.cn/) reflected an emerging recognition of the importance of technology for teaching. After each session, the student teachers were asked to write blogs to reflect on what they had learnt. The blogs showed that the student teachers were engaged in in-depth thinking about the role of technologies in education:

As teachers and educators, it is impossible for us to ignore the progress of the society. This means that we should develop the understanding on how our students would behave, think and live, and master the tools that our students are using to express themselves and communicate with others, then summarise educational meaning from it... A critical issue is when we attempt to identify the relationship between education and technology, we should always remember that education should be at the centre, and it is not a subordinate factor to technology.

In the new era that technologies are developing so quickly, we have to recognise that learning and teaching should take the advantage of technology development... A successful class should effectively take advantage of technologies to develop students' skills for the 21st century.

\section{Conclusion}

Technology is developing greatly in the new information age. Modern Educational Technology as an selective course in universities needs to be updated constantly to adapt to the technological improvements. Also, it can be a role model for other courses in terms of technology application and integration. The improvement of the course has set up a relatively stable framework for the following years. Nevertheless, many aspects of curriculum still need to be explored and further improved in the future, such as how to effectively use new technological tools to support different subjects and how to integrate new devices (e.g. mobile devices, e-schoolbag, voting machines, and electronic whiteboards) into subject teaching and learning.

\section{References}

Chen, M. (2006). Research on innovation and practice of educational technology capabilities development model for student teachers. E-Education Research, Issue 3, 22-24, 50. http: / / caod.oriprobe.com / articles / 20747524/shi_fan_sheng_jiao_yu_ji_shu_neng_li_pei_ya ng_mo_shi_de_chuang_xin_yu_htm

Cheng, L. (2007). The study on educational technology capabilities development for student teachers. Lanzhou: North West Normal University.

Dodge, B. (2002). WebQuest taskonomy: A taxonomy of tasks. http: / / webquest.sdsu.edu/taskonomy.html [viewed 20 Jan 2012].

Kennedy, G. E., Judd, T. S., Churchward, A., Gray, K. \& Krause, K.-L. (2008). First year students' experiences with technology: Are they really digital natives? Australasian Journal of Educational Technology, 24(1), 108-122. http:/ / www.ascilite.org.au/ajet/ajet24/kennedy.html

MOE (2004). Educational technology competency standards for teachers (Trial). [viewed 20 Jan 2012; in Chinese]. http: / / www.pep.com.cn/xgjy/jiaoshi/jydt/201008/t20100827_803018.htm

Tapscott, D. (1998). Growing up digital: The rise of the net generation. New York: McGraw-Hill. 
Van Merriënboer, J. J. G., Clark, R. E. \& de Croock, M. B. M. (2002). Blueprints for complex learning: The 4C/ID model. Educational Technology Research and Development, 50(2), 39-61. http: / / dx.doi.org/10.1007/BF02504993; also at http: / / www.cogtech.usc.edu / publications/_clark_4cid.pdf

Van Merriënboer, J. J. G. \& Kester, L. (2007). Whole task model in education. In Handbook of research on educational communications and technology, 3rd Edition. New York, NY: Lawrence Erlbaum Associates, 442-446.

Van Merriënboer, J. \& Kirschner, P. A. (2008). Four component instructional design (4C/ID). SciTopics, September. [viewed 20 Jan 2012].

http://www.scitopics.com/Four_Component_Instructional_Design_4C_ID.html

Zhang, Q. \& Chen, P. (2008). The problems and solutions in "Intel teach to the future" for the normal university students. Journal of Educational Science of Hunan Normal University, Issue 3, 79-83. http: / / open.oriprobe.com/articles/14146225/ details.htm

Zhao, G. (2010). Research on educational technology capabilities development model for student teachers in higher education. China Teacher Human Resources Research in Higher Education, June, 40-44.

\author{
Authors: Hanbing Yan \\ College of Distance Education \\ Modern Educational Technology Center \\ East China Normal University, Shanghai \\ Email: yhb1225@hotmail.com Web: http:/ / www.ecnu.edu.cn/english/ \\ Yumin Xiao \\ School of Education Science \\ East China Normal University, Shanghai \\ Email:ymxiao@ses.ecnu.edu.cn Web: http:/ / www.ecnu.edu.cn/english/ \\ Associate Professor Qiyun Wang \\ Learning Sciences and Technologies, National Institute of Education \\ Nanyang Technological University, 1 Nanyang Walk, Singapore 637616 \\ Email: qiyun.wang@nie.edu.sg Web: http:/ / www.nie.edu.sg/profile/wang-qiyun \\ Please cite as: Yan, H., Xiao, Y. \& Wang, Q. (2012). Innovation in the educational \\ technology course for pre-service student teachers in East China Normal University. In \\ C. P. Lim \& C. S. Chai (Eds), Building the ICT capacity of the next generation of \\ teachers in Asia. Australasian Journal of Educational Technology, 28(Special issue, 6), 1074- \\ 1081. http: / / www.ascilite.org.au/ajet/ajet28/yan.html
}

